\title{
Negotiating the Local and Global in Nepalese EAP: Inherent Ideological Tensions and Possible Pathways
}

Madhav Kafle

\begin{abstract}
This article explores ideological tensions and possible directions to solutions in Nepalese EAP pedagogy in the context of increasingly interdependent world. Seventeen EAP professionals responded to a qualitative online survey disseminated through the Nepal English Language Teachers' Association listserv, personal emails and other social networking sites. Data was analyzed from the perspective of language ideologies. The main ideological tensions as indicated by the teachers are grouped under three interrelated headings: top-down imposition, buying into Standard English as a panacea for all problems, and disconnect between policy and practice. Based on these findings, the article argues that whereas the top-down imposition is connected with the ideology of development, buying into Standard English with ideologies of linguistic fixity and purism, and the disconnect between policy and practice with the ideology of nationalism and language ownership.
\end{abstract}

Keywords: EAP in Nepal, tensions, ideologies, multilingual setting, local/global

\section{Introduction}

English for academic purposes (EAP) is defined by some scholars as the teaching and learning of academic English in higher education, specifically aimed for undergraduate and graduate international students. Other scholars define EAP broadly and say it can include a host of situations. According to Hamp-Lyons (2011, p.89), EAP is "an eclectic and pragmatic discipline: a wide range of linguistic, applied linguistic and educational topics can be considered from the perspective of English for academic purposes, or drawn in methodologically to inform EAP." HampLyons goes on to cite "classroom language, teaching methodology, teacher education, assessment of language, needs analysis, materials development and evaluation, ... research writing and speaking at all academic levels, the sociopolitics of English in academic uses and language planning" (p. 89) as various areas where EAP can be used. Similarly, Carkin (2005), citing Dudley-Evans and St. John (1998), lists at least four different contextual possibilities of EAP: EAP in those countries where English is a native language, EAP in those countries where English has been established as a national language, EAP where English neither of the previous two but is used as the language of instruction throughout the education system, and EAP used in teaching specialty subjects such as medicine, technology, engineering, and science. The latter two situations pertain to Nepalese context, where English has been given utmost importance in education system and English 
materials are used in scientific and technical advanced education, even when English is not necessarily the medium of instruction as texts in languages other than English can be scarce in those fields. For detailed descriptions about types of EAP see Basturkmen (2010), and Paltridge and Starfield (2013, introduction).

Next, I need to clarify what I mean by language ideologies as it is presumably one of the most contested terms among the group of terms such as attitudes, beliefs, myths, ideologies often found in scholarly literature regarding conceptions of lay people about language and literacies. These terms tend to carry the baggage of different research traditions. For example, attitude is commonly used in social psychological tradition and is viewed as an implicitly held stance toward something. While some social psychologists use attitudes and beliefs interchangeably, others see attitude as an umbrella term for cognition (belief), affect, and behavior (Baker, 1992; Garrett, 2010; Wilton \& Stegu, 2011). In Second Language Acquisition, "learner beliefs" tend to be used synonymously with "folk linguistic theories of learning" (Miller \& Ginsberg, 1995), "learner representations," "cultural beliefs," and "culture of learning." In sociolinguistics, Watts (2011, p. 16) defines language myths as "communally shared stories that, regardless of their factual basis, are believed and propagated as the cultural property of a group." Linguistic anthropologist Kroskrity (2010, p. 192) defines language ideologies, as "beliefs, feelings, and conceptions about language structure and use which often index the political economic interests of individual speakers, ethnic and other interest groups, and nation states." This definition is particularly useful, because while attitudes and beliefs tend to be associated with individual dispositions, ideologies can be associated to both individuals and groups. I am using language ideologies in Kroskrity's sense in this article.

Study of existing scholarship shows that there is a lack of literature that assesses problems and prospects of Nepalese ELT practice from the perspective of language ideologies. Although there is a relative dearth of such literature, existing literature has identified several challenges faced in ELT classrooms in Nepal: large classes and lack of adequate teaching resources (Giri, 2010); inadequacy of professional development (Bhattarai \& Gautam, 2005); neglect of local needs (as recently seen in NELTA Yahoo group and Choutari discussions). Other problems include the determination of the variety of English to be taught, the selection of methodologies that best suit Nepalese contexts (Giri, 2010) and the enormous gap between the proficiency of learners coming from private schools and those from public or government schools. However, studies that have asked the teachers themselves about the problems and challenges, particularly in EAP practice, are just beginning to appear. This study, I hope, will be useful in continuing the conversation regarding negotiating tensions in EAP practice in Nepal.

\section{Contextualizing the study}

This study was conducted by using an online qualitative survey, which was disseminated through the NELTA Yahoo group, emails and social networks. The survey included several focus questions (see below) asking teachers to describe various aspects of their experiences of teaching EAP in Nepal, including the challenges and tensions, and their perspective on Nepalese EAP. The survey focus questions were:

1. What problems have you experienced so far regarding teaching English (for 
academicpurpose) in Nepal? How have you overcome them?

2. How do you negotiate tensions (if any) between global EAP/ELT practices and local circumstances?

3. What prospects do you see for teaching English for academic purposes in Nepal?

4. With the increasing trend of internationalization of higher education world wide in what ways can Nepal better prepare itself in terms of teaching English for academic purposes?

An overview of all these questions is already discussed in a book chapter written for a volume that deals with EAP practices in Asia (Kafle, 2014). That chapter discusses various challenges Nepalese ELT teachers face such as huge class sizes, lack of teaching materials and resources (e. g. technology and even infrastructure), and how teachers solve them. In this paper, I would like to take the discussion further by analyzing tensions or problems teachers reported through the lens of language ideologies.

Seventeen participants, among whom were nine college and university professors, six higher secondary teachers, and two secondary teachers, took part in the study. It should be noted that the participants selfselected themselves as EAP professionals while completing the online survey but there was no any follow-up question to justify their choice. The participant responses were compiled in a single file and coded thematically on four major areas: problems, tensions, prospects, and internationalization. While they are interrelated, in this paper, I emphasize on problems and tensions. I need to acknowledge upfront that the findings in this paper are not supposed to be definitive as the sample is low and diverse. Additionally, since all the survey was conducted online, it has yet to integrate the voices of many teachers who did not have affordances of the internet. However, even in such a lower scale, findings from this study should be useful in furthering the much needed critical conversation regarding how to strike a balance between the local practice and global discourses of English.

\section{Inherent ideological tensions: excerpts from the survey}

At the outset, I would like to clarify that this section includes both the results and preliminary analysis. It provides not only the key excerpts from the corpus of data, but it also tries to reach to the root of the problem by connecting what the teachers said (micro) to what the overall Nepalese ELT milieu (macro) is. Therefore, my focus here is to enter into in-depth about the tensions teachers felt and then seek possible reasons why problems indicated by the teachers exist the way they do. I will group the main tensions teachers expressed under three interrelated headings: top-down imposition, buying into Standard English as a panacea for all problems, and disconnect between policy and practice.

Top-down imposition: The first problem, according to the teachers, is created by the imposition from the top in virtually all areas of education. According to HN (I use coded abbreviations to refer to my study participants), "There are multiple problems, but the most crucial one is ELT in Nepal is top-down. Teachers are not provided any significant role to play in all 
aspects" (HN). So, is the issue here only centralization? Is it the case in English only? Similarly, RL reiterates HL when he says:

Regarding to the designing of the curriculum, mostly top down approach is followed. Therefore, as a teacher, we may give feedbacks or our impressions of the syllabus if the authorities at TU hold some kind of seminars before they implement any syllabus. So I do not have experience of designing curriculum. Regarding to implementations of the curriculum, I have faced a number of challenges. (RL).

Both HN and RL emphasize that they do not have much agency in implementing the pedagogy they see locally relevant. It seems that authorities consider teachers more as mechanical entities than active role players in the whole process of designing and implementing the curriculum. As RL points out, no feedback is sought from the teachers about the prospective courses. Neither is consultation taken from the students: "There are a lot of problems I have experienced so far regarding teaching English in Nepal. To be specific, large classroom and imposed curriculum without consulting the students based on their needs and requirements" (YP). Similarly, SM says that "It is highly top down. It feels that the curriculum and syllabus is prepared without considering the real needs of students because I do not remember if any research has been done to assess the needs of students and teachers" (SM). Thus, it seems that the main stakeholders in the process of teaching and learning cannot participate in their own journey meaningfully.

Authorities responsible for academic decisions do not wish to hear experiences of the main people involved in the education. Top-down imposition of curriculum disables designing of curriculum befitting to the local context. When curriculum is imposed without necessarily establishing any connection with needs and proficiencies of students, teachers struggle not only with the goals and objectives of courses, but also with the teaching materials and methods. To be fair to the state and government, we need to acknowledge that the funding mechanism for a country whose budget relies on foreign donation, and therefore centralization has been in the hold. So rather than on research, the curriculum of the country has been so far run on the proposition that English is good on all counts. We, that is all English language professionals, should point out what could be better alternatives in such situations.

While many institutions around the globe provide autonomy to teachers, it is imperative to discuss why Nepalese administrators do not create such an environment. I argue that such top-down imposition is connected with the ideology of development. I am using the term development satirically here as government authorities tend to conflate development with Englishization or mimicking of "western" practices. English is often perceived as a vehicle for both individual and national development and equated with success in many countries in South and Southeast Asia (Sung, 2012), including in Nepal. In other terms this can also be labelled ideology of economic benefit. Without English literacy, education in only local languages seems to be treated as an utter failure as indicated by the public's feverish craze of English, which exists in other countries such as Korea and China as well (Park, 2009; Hu, 2009). Nepal's recent move to introduce English education from grade one in government schools also speaks about this issue. While we can see extensive use of English in the Nepalese society, the fact that governmental authorities do not listen to teachers and students tells us essentially that we can never 
become language users and simply remain language learners.

Standard English as a panacea for all problems: Next, fascination with Standard English practice is prevalent at both lay and expert levels in Nepal. By Standard English practice, I mean the ongoing wholesale implementation of dominant teaching methods and materials in Nepal. Our goals and objectives are targeted at attaining a nativelike proficiency in English, thus obsession with utterings and manners of a white-skinned person. AM finds the attitude of learners towards the teacher of non-native teachers problematic because "many learners think that native teachers are far better than the nonnative teachers" (AM). Despite the current reality of English being a family of languages (Crystal, 2004), we subscribe to a monolithic fixed and idealized native speaker. Consequently, particularly in the public schools English has become an unattainable goal as one of the teachers says: "English should not be presented as a vampire that hunts every single student particularly in a rural area. Like Nepali, it simply is a language. Overcoming this psychological problem first would be fruitful for making English teaching easier in Nepal" (KB). Not only the folks, but also the government and policy makers, seem to be easily buying in to that instruction in English is the best way of schooling as $A B$ describes:

English as a subject and a medium of instruction has morphed into a complex area in Nepal. In the name of communicative competence and quality improvement, both government and private sectors have given over emphasis on its role in education both in terms of time and resources. In comparison to the investment, there has been little improvement in the quality of and skills in the use of English. The overemphasis on the English only medium has been at the cost of our national languages and quality of learning. My observation is that in the private schools, students have problems in understanding the basic concepts in the content areas like Social Studies and Science not because the topic itself is so difficult but primarily because the teacher fails to make them understand in English. (AB)

I quote $\mathrm{AB}$ in length because the excerpt raises at least three important points: conflation of quality with Standard English, repercussion to multiples languages, and ground reality of English not doing the magic. It seems as if being educated means only to be able to communicate in English. While thousands of students cannot pass their annual exams simply because of untenable expectations of Standard English, what teachers like AB have been saying is rarely taken into account. Using a language that creates a fence between the majority of students and teachers and pervades understanding is tantamount to a mockery of ourselves.

Such buying into Standard English (Pendergast, 2008) is connected with ideologies of linguistic fixity and purism. The ideology of fixity of language views languages as separate systems and ideology of purism renders mixing of languages as contamination. In multilingual settings like Nepal, contact between languages has been going since antiquity and hybridity is the norm. However, when our own policy makers accept the hegemonic practices, education stands for teaching for the test and failing thousands of students annually simply because they cannot confirm to the native speaker norms. By consciously or unconsciously promoting Standard English, current ELT practice disregards multilingual learners' full potentials as asking them to communicate like a native speaker is an unrealistic goal. The argument here is not that English is not important, but simply that we should be reflective of the language practices in Nepalese society, 
as participants of this study urge. When the masses of people are engulfed by folk attitudes that native speaker is considered the eventual target, it creates a sense of professional illegitimacy and insecurity in teachers.

Disconnect between policy and practice: Because of the previous two reasons, we have a third reality: we face unrealistic methods and materials. Even at the university level these contradictions are common as RL reveals:

Sometimes, we have challenges simply because we have prescribed the Western author's book. For example, we have prescribed Mitchel and Myles's book entitled Second Language Acquisition. No doubt, the book is very good, but beyond the capacity of our learners, because, it contains a lot of citations, almost every lines. Thus, the students who have some background knowledge of SLA can understand, but others have very difficulties. (RL).

RL raises the issue of academic discourse and knowledge production. As our society is primarily oral one and teaching oriented, the textbooks that were produced in the literacy and research dominant communities do not suit well to our context. Therefore, "The imposition of English as a medium of instruction-plus communication - is incompatible with the reality of the Nepali society where students learn and speak very fluently multiple languages without the same kind of "enforcement" for 10-15 years" as SG opines.

The final tension is due to the ideology of nationalism and language ownership. Despite Nepal being a multilingual country, the discourse of nationalism has cultivated such a conception that a country should have a language. To simplify, since Nepal is a country, Nepali (or others) is the mother tongue of Nepalese people; therefore they cannot own English in any way. Nationalism not only erases linguistic diversity within a country but also blocks owning other languages labelling them foreign. While English was a foreign language to Nepal at one point, it is not so anymore. Postmodern theorists have shown that languages are always in the move and language belongs to those who use it (Pennycook, 2007; Blommaert, 2010). In the current context of increasing global interdependence, only the Standard English is not adequate; therefore teaching and learning English means inculcating plurality of practices.

To summarize the findings, top-down imposition has been validated in the name of social, economic, and educational development when in reality English is just a part of the discourse. Next, because the language modernization in itself is a construct imported from monolingual settings, the act of seeing Standard English as a panacea for all problems would be in vain in multilingual settings like Nepal. The prior two causes invite a third consequence: disconnect between monolingual policy and heteroglossic practice that is seen in most academic venues in Nepal.

\section{Possible pathways: further discussion}

I have cursorily discussed above prominent tensions as teachers perceived it. In the following section I attempt to discuss possible directions to negotiate those challenges. As CK says, "Now is the time for curricular innovation by local scholars and writers, theorization of local methodologies and practices, look for various options for teachers' professional development in the globalized world." If that be so, and as other participants in this study also indicate we need to explore the 
ways of negotiating the imposition, of dealing with fixity, and of destabilizing the national/ purist discourses.

Negotiating Imposition: As we saw above, participants pointed out that there is disturbing imposition from the top mainly due to the false ideology of development discourse. This ideology has some repercussions: first teachers cannot provide their feedback as their voice is not heard. This is ironic because they are the main knowledge facilitators and at the same time they are not given any platform to have their say. However, if we look at globally, it has been agreed that nonnative teachers are as good as the native ones and they can provide a good education as long as they have required training.

The first necessity is researching our current practices and realities to see how English is being localized in the Nepalese context but with awareness of global developments. Thus, our major challenges remain developing locally informed and situated practices: that is imagining multilingual schools (García, Skutnabb-Kangas, \& Torres-Guzmán, 2006). We need to know how dominant methodologies are being adapted, so we need critical ethnographies. That way we can make the teaching an informed and situated social practice. Despite the imposition from the top, teachers reported they have been doing what they can to localize the teaching materials and methods. We need research that explores the rise and efficacy of our approaches. Global or dominating methodologies may not always work. For example, Ramanathan (2005) highlights the role of choral repetition in India; Nishino and Watanabe (2008) emphasize the importance of grammar translation in Japan; Chen, Warden, and Chang (2005) show how examination-oriented motivation can work in better terms in Taiwan. We can build on these examples and conduct research to fulfil the gap in Nepalese ELT. While undoing the imposition at once might be impossible and impractical, we need to be able to draw ontologically and epistemologically from our own ecology. In other words, we need to be able to recommend to the government/ policymakers that we need this kind of pedagogy. This suggestion is not meant to be a definitive answer for all the contexts but an alternative way of making English local.

Next, needs analysis in the changing context should be recurrent to make sure our practices are not out of sync with the societal linguistic hybridity. As SM opines, "MOE, TU, HSBC, CDC or any other stakeholders, I personally feel that, needs to carry out the needs assessment, design curriculum and syllabus that fits the needs of students and teach accordingly" (SM). Institutions SM names might not prioritize conducting the research in the name of lack of resources, but we should seek alternatives including encouraging graduate students to do empirical research rather than the common archival one. We need to seriously think about how we can establish a culture of doing research for the professional development of teachers. Therefore, it is quite urgent to discuss locally how we can strive to move to that direction.

Dealing with fixity: We also saw that in a multilingual country like Nepal, we have been asking our students to be like an idealized native speaker, where language is a fixed entity. This probably is going to be the most challenging issue we will have to face, even in the so called center, the translingualism has just started. In the past, it took decades to be aware of the practices from research dominant countries. For example, we still have a legacy of fierce attraction towards CLT, which in the norm- 
providing countries has now largely been eschewed. But today, mainly because of the space and time compression, the interchange happens in a more rapid speed thus power of the traditional center has been shifting. So, it is time to reflect about why we are using the methods and techniques we are currently espousing. With that understanding, we can aim to develop our context sensitive pedagogies.

We should not however forget to ask fundamental questions including what counts as English in a multilingual context. Related to this is the problem of assessment: what does it mean to be proficient in English now, 10 years from now and 100 years from now? While we need empirical studies to establish the direction concretely, it would not be remiss to say there is no other option than building on plural (heteroglossic) practices. Others have already started redefining English elsewhere (Saraceni, 2010). Plurality of practices framework can draw from a range of theoretical frameworks, including intercultural communication, World Englishes, English as a lingua franca, and multivocality. As sociolinguist Bhatt argues, "[T]he field of world Englishes reevaluates, critiques, and displaces the earlier tradition of cross-cultural and crosslinguistic acquisition and use of English, its teaching, and its transformations" (2001, p. 544). Similarly, for Matsuda (2003, p. 727) World Englishes "is, rather, a different way of looking at the language, which is more inclusive, pluralistic, and accepting than the traditional, monolithic view of English in which there is one correct, standard way of using English that all speakers must strive for." We now also have evidence from English as a Lingua Franca research that interlocutors "engage in communication strategies and accommodation processes that are unique to this context and that may conflict with the ways in which NSs typically negotiate understanding" (Pickering, 2006, p. 227).
Therefore, we now do have adequate theoretical frame to relocate English and to explore the multivocality (Higgins, 2009) it entails.

Such approaches build on hybrid semiotic practices, destabilize the concept of the monolithic standard, and shift goals of teaching from mastery of target norms to effective negotiation of divergent communicative practices. They also raise possibility of giving credence to what students and teachers frequently do in their classrooms and of letting them decide how they can best connect their local needs and global demands. I am aware that not everyone will buy into the paradigm of plurality. But as Pennycook (2008) says, English is a language always in translation; meaning it takes diverse forms as it has been doing historically. Therefore, rather than keep looking at English as a foreign language, we need to see English as a local language.

Destabilizing discourses of nationalism and language ownership: In our day to day lives, we tend to assume that a person living in a country called Natal speaks Natali or whatever dominant language spoken in that country. But at times, we erase many people who reside in the same country and speak multitude of languages simply because the majority of the world sees the ethnicity/nationality-language equation as natural. However, in a global village, the western concept of one nation one language has already started to become untenable. Because of time-space compression, deterritorialization, migration, and advancement in internet connection, languages have become even more mobile as are people. English has also been a local language where it used to be a business language initially.

Our goal in teaching English is to make people negotiate a range of Englishes and aspire to be a cosmopolitan. As LS says, since 
"the number of students who would like to go abroad is increasing every year, the knowledge of EAP course would be quite handy for them" (LS). Therefore, we need to show vignettes from successful multilingual people. Looking into the lives of successful biliterate professionals (Belcher \& Connor, 2001), it seems evident that having a multilingual repertoire is going to be the most pragmatic and humane, if we are to participate in global interaction. While I do not mean to take the West a point of reference but we need to just know what has been going on in other parts of the world. Many researchers are now questioning the significance of nationstate oriented pedagogy in different levels (e.g. Spolsky, 2012, especially, part IV).

\section{Conclusion}

The problems raised by the teachers in this paper are not typical to Nepal only. In fact, such scenarios have been reported across the globe where English is not used as a first language. We have to be in conversation with colleagues elsewhere to collectively explore how a multilingual/bilingual/ polylingual/heteroglossic pedagogy helps developing context relevant approaches. Without convincing both the lay and expert groups, what I have argued here, might be a contradiction: What I have presented here might not be translatable to the teachers who are forced to teach to the exam. Yet, they probably would not have to be that anxious for adjustments they are already doing in their classes, if we can develop a culture of local research. And we need to do away with the misconception that research is not feasible in developing countries like ours. In fact, we could start seemingly simple strategies such as keeping diaries, or some sort of logs where teachers reflect about their practices and problems. Of course, teacher trainers (who themselves might have to be trained accordingly first) would have to put an ostensible effort to address the tensions raised by the teachers.

As teachers involved in this study have indicated, letting teachers and learners have their say in the academic process is one of the key issues if we are to build bottom-up practices so that we can participate effectively in a globalized world. Because, we are bound to face both localization and globalization discourses in all areas and bottom up practices would mediate the hegemonic ELT approaches. This indicates a need of training the teachers for teaching in the new conditions. Such training might entail telling how a local language has now become a global one and only future holds the truth of how long a language can have its sway. Canagarajah (2005, p. 13) maintains that "Local knowledge is a process - a process of negotiating dominant discourses and engaging in an ongoing construction of relevant knowledge in the context of our history and social practice." So, at this point Nepalese ELT professionals have to be engaged in discovering our own situated bases of teaching English that suit our local needs. As Tupas (2014) argues local teachers and classrooms should be the source of information for the problems of teaching language rather than they just be recipients of dominating knowledge. To that end, we should not only work collaboratively on (discovering and) sharing our own practices, we should also make concerted efforts to establish and support local scholarship.

To establish scholarship at the local level, we should strive to explore not only the currently available literature in English but also unpublished or published literature in other languages as well. There was a time when we did not know what goes on beyond our immanent borders and the knowledge came from a center, but today the mode of knowledge production is substantially different from old days; therefore we should 
reach out to alternative centers or create centers of our own. Answers about what to teach and how to teach must come from such reflective research and should not be based on mere mimicry of approaches used in industrialized nations.

\section{Acknowledgements}

I would like to the thank all the 17 participants who managed to be save their precious on screen time despite the perennial load shedding going on in the country at that time. Thanks are also due to the anonymous reviewers and editors, especially to Dr. Prithvi Shrestha, for their constructive feedback during the revision. Any weaknesses and limitations are, of course, mine.

\section{About the author}

Madhav Kafle is a doctoral candidate in Applied Linguistics at The Pennsylvania State University, USA. Before going to the USA for his graduate studies, he taught English at both rural and urban academic institutions in Nepal. His research interests include multilingual academic literacies, global spread of English, and critical pedagogy.

\section{References}

Baker, C. (1992). Attitudes and language. Philadelphia: Multilingual Matters.

Basturkmen, H. (2010). Developing courses in English for specific purposes. New York: Palgrave Macmillan.

Belcher, D. D., \& Connor, U. (2001). Reflections on multiliterate lives. Toronto: Multilingual Matters.

Bhatt, R. M. (2001). World Englishes. Annual Review of Anthropology, 527-550.

Bhattarai, G. R., \& Gautam, G. R. (2005). English language teachers at the crossroads. Journal of NELTA, 10(1-2), 1-5.
Blommaert, J. (2010). The sociolinguistics of globalization. Cambridge, UK: Cambridge University Press.

Canagarajah, A. S. (2005). Reclaiming the local in language policy and practice. Mahwah, N.J: L. Erlbaum Associates.

Carkin, S. (2005). English for academic purposes. In E. Hinkel (Ed.), Handbook of research in second language teaching and learning Vol. I (pp. 85-98). Mahwah, NJ: Lawrence Erlbaum.

Chen, J. F., Warden, C. A., \& Chang, H.-T. (2005). Motivators that do not motivate: The case of Chinese EFL learners and the inûuence of culture on motivation. TESOL Quarterly, 39, 609 - 633. doi: $10.2307 / 3588524$

Crystal, D. (2004). The language revolution. Cambridge, MA: Polity Press.

Dudley-Evans, T., \& St. John, M. (1998). Developments in ESP. Cambridge, UK: Cambridge University Press.

García, O., Skutnabb-Kangas, T., \& TorresGuzmán, M. E. (2006). Imagining multilingual schools: Languages in education and glocalization. Clevedon: Multilingual Matters.

Garrett, P. (2010). Attitudes to language. Cambridge, UK: Cambridge University Press.

Giri, R. A. (2010). English Language Teachers' Resource Centre: A Model for Developing Contexts. Journal of NELTA, 15(1-2), 64-76.

Hamp-Lyons, L. (2011). English for academic purposes. In E. Hinkel (Ed.), Handbook of research in second language teaching and learning, Vol. II (pp. 89-105). New York: Routledge.

Higgins, C. (2009). English as a local language: Post-colonial identities and multilingual practices. Bristol: Multilingual Matters.

Hu, G. (2009). The craze for English-medium education in China: Driving forces and 
looming consequences. English Today, 25(04), 47-54.

Kafle, M. (2014). EAP in Nepal: Practitioner perspectives on multilingual pedagogy. In I. Liyanage \& T. Walker (Eds.), English for academic purposes (EAP) in Asia (pp. 51-64). Boston: Sense Publishers.

Kroskrity, P. V. (2010). Language ideologies-Evolving perspectives. In J. Jaspers, J. Verschueren, and J.-O. Ostman (Eds.), Society and language use (pp.192-211). Amsterdam: John Benjamins.

Matsuda, A. (2003). Incorporating World Englishes in teaching English as an international language. TESOL Quarterly, 37(4), 719-729.

Miller, L., \& Ginsburg, R. (1995). Folklinguistic theories of language learning. In B. Freed (Ed.), Second language acquisition in a study abroad context (pp. 293-315). Amsterdam: J. Benjamins.

Nishino, T., \& Watanabe, M. (2008). Communication-oriented policies versus classroom realities in Japan. TESOL Quarterly, 42, 133-138.

Paltridge, B., \& Starfield, S. (Eds.). (2013). The handbook of English for specific purposes. Chichester, UK: John Wiley \& Sons.

Park, J. K. (2009). 'English fever' in South Korea: its history and symptoms. English Today, 25(01), 50-57.

Prendergast, C. (2008). Buying into English: Language and investment in the new capitalist world. Pittsburgh: University of Pittsburgh Press.

Pennycook, A. (2007). Global Englishes and transcultural flows. New York: Routledge.

Pennycook, A. (2008). English as a language always in translation. European Journal of English Studies, 12(1), 33-47.
Pickering, L. (2006). Current research on intelligibility in English as a lingua franca. Annual Review of Applied Linguistics, 26, 219-233.

Ramanathan, V. (2005). Seepages, contact zones, and amalgam: Internationalizing TESOL. TESOL Quarterly, 39, 119 - 123. doi:10.2307/ 3588455

Saraceni, M. (2010). The relocation of English: Shifting paradigms in a global era. New York: Palgrave Macmillan.

Spolsky, B. (Ed.). (2012). The Cambridge handbook of language policy. Cambridge: Cambridge University Press.

Sung, K. (2012). Critical practices in Asia: A project of possibilities in the era of world Englishes. In K. Sung \& R. Pederson (2012), Critical ELT practices in Asia (pp. 23-54) Rotterdam: Sense Publishers.

Tupas, R. (2014). The Unequal Production of Knowledge in the Sociolinguistics of Englishes. In R. Marlina \& R. A. Giri (Eds.), The pedagogy of English as an international language (pp. 159173). Victoria, Australia: Springer.

Watts, R. J. (2011). Language myths and the history of English. New York: Oxford University Press.

Wilton, A., \& Stegu, M. (2011). Bringing the folk into applied linguistics: An introduction. AILA Review, 24(1), 1-14. 